\title{
Neisseria gonorrhoeae identified by the direct fluorescent antibody technique in male contacts
}

\author{
WERA ENFORS, GUNNEL ERIKSSON, T. KAAMAN, AND G. vON KROGH \\ Department of Dermatology, Södersjukhuset, Stockholm, Sweden
}

A high frequency of increased resistance of $N$. gonorrhoeae to antibiotics has been reported from several countries (Willcox, 1970). This is not the case in Sweden, but the number of asymptomatic cases has become a problem. Among male patients, at least 10 to 20 per cent. have no symptoms at the time of diagnosis (Hansson, 1971). The majority of these persons do not suspect that they have contracted gonorrhoea, but they are sources of infection and may develop complications of the disease. According to the Swedish Law against Infectious Diseases, named contacts of patients proved to have gonorrhoea must be examined. The recommendation is that two cultures in men and three in women must be negative before the possibility of a gonorrhoeal infection is eliminated. In a group of male contacts of cases of gonorrhoea Pariser, Farmer, and Marino (1964) found that 98 of 115 cases were asymptomatic. Molin (1970) found that more than half of the male contacts were asymptomatic, whilst the corresponding figure for patients attending voluntarily was approximately 4 per cent.

Reports on the frequency of prostatic involvement in gonococcal urethritis vary (Höfer, 1954; Starck, 1966; Heijer, 1967; Landgren, Molin, and Nyström, 1971). Half of the patients in Heijer's series had no subjective discomfort. Furthermore, a normal finding on digital examination of the prostate gland does not exclude an inflammatory process (Romanus, 1952; Stamey, Govan, and Palmer, 1965). Thus the possibility of clinically silent gonococcal prostatic involvement must not be neglected.

The purpose of this study was to try to find out if the direct fluorescent antibody technique would make it possible to detect additional patients infected with $N$. gonorrhoeae and thereby reduce the spread of the infection and possibly also the development of complications. All men referred to the venereal out-patient clinic at Södersjukhuset, Stockholm, as contacts of gonorrhoea patients over a period of 8 months, have been investigated by this method when direct microscopy and cultures of urethral specimens had been negative at two consecutive visits.

\section{Material and methods}

PATIENTS

From October, 1971, to May, 1972, 167 men were referred to the clinic as suspected contacts of patients with gonorrhoea under the Swedish Law against Infectious Diseases.

\section{CLINICAL PROCEDURE}

All patients were asked when they had had any earlier treatment with antibiotics.

Specimens from the urethra were examined for gonococci by direct microscopy after staining with methylene blue, and by culture. Patients positive at the first or second visit were excluded from the study but were of course treated for gonorrhoea. At the second visit after an interval of at least 1 week, specimens from the urethra of the hitherto negative patients were collected for the direct fluorescent antibody (FA) test with cottonwool-tipped wooden sticks moistened in saline.

Prostatic massage was carried out after micturition by the method of Romanus (1952), and specimens were taken for direct microscopy, culture, and the FA test. Regarding the specimens taken after prostatic massage the FA test was read only in cases in which the second culture also turned out to be negative. The urethral FA smears were examined only in those patients who had a positive FA test in specimens collected after prostatic massage.

\section{BACTERIOLOGICAL PROCEDURE}

The specimens were collected with a charcoal swab, transferred to modified Stuart's transport medium (Ringertz, 1960), and cultured on chocolate agar and also on chocolate agar with ristocetin and polymyxin B according to Thayer-Martin's method. The plates were incubated at $36^{\circ} \mathrm{C}$. in an atmosphere containing 5 per cent. $\mathrm{CO}_{2}$ and read after 20 and $48 \mathrm{hrs}$. The identification of $N$. gonorrhoeae was based on colony appearance, the 
oxidase test, the Gram stain and fermentation tests. $N$. meningitidis could thus be excluded. Sensitivity tests were performed using the quantitive disc method of Ericsson (Ericsson and Sherris, 1971).

\section{FLUORESCENT ANTIBODY (FA) TEST}

This was performed according to Danielsson (1963) with slight modification: fluorescein-isothiocyanate (FITC)labelled antigonococcal globulin was obtained from the National Bacteriological Laboratory. The optimal dilution was established for every new batch of conjugate by so-called 'FA titration' on smears from 24-hr cultures of gonococci. In order to counterstain the smear and eliminate false positive reactions, an equal volume of lissamine rhodamine B (RB 200)-stained antistaphylococcal globulin (from the National Bacteriological Laboratory) diluted $1: 2$ with phosphate-buffered saline at $\mathrm{pH} 7 \cdot 4$ (PBS) was added to the diluted FITC-antigonococcal globulin and then the conjugate was filtered through Millipore Filters ${ }^{\star}$, pore size $0.8 \mu$. The air-dried smears were covered completely with conjugate. The slides were placed in a damp chamber at room temperature for 45 min., rinsed thoroughly in PBS, and then washed in the same medium for $10 \mathrm{~min}$. The slides were dried and mounted under a cover-slip with phosphate-buffered glycerol.

\section{FLUORESCENCE MICROSCOPY}

This was carried out with the aid of the Zeiss laboratory microscope, standard RA, equipped with a dark-field condenser, high pressure mercury lamp HBO 200, excitation filter BG 12, and barrier filters. Smears were scanned using a low-power objective and suspect areas were examined at a magnification of $\times 500$. The degree of fluorescence was recorded from intensely yellowishgreen to barely distinguishable by the method of Danielsson (1963), but the criteria for the identification of $N$. gonorrhoeae in this study were that the fluorescence had to be intense, the coccal morphology had to be intact with the edges well-defined and a dark central zone, and the size had to correspond to that of stained gonococci in smears taken from $24-\mathrm{hr}$ cultures. These strict criteria were established to eliminate diagnostic errors, such as non-specific stained particles, FITC-aggregations, and artefacts. Thus all smears not fulfilling these criteria were counted as negative. In the majority of specimens accepted as positive, the fluorescing organisms were mostly extra-cellular; the site of the organism was not considered important so long as the above criteria were satisfied. Before being counted as negative, a smear was examined for 15 to $20 \mathrm{~min}$.

\section{Results}

Gonorrhoea was diagnosed after the first examination in sixty of the 167 males reported as contacts and in whom investigations were performed by direct microscopy and routine culture (Table I). Of these 60 patients, 32 had symptoms of urethritis in the

\footnotetext{
${ }^{\star}$ Millipore Corporation, Bedford, Massachusetts.
}

TABLE I Results of direct microscopy and routine cultures at two consecutive examinations in 167 males reported as contacts of gonorrhoea patients

\begin{tabular}{|c|c|c|c|}
\hline \multirow[t]{3}{*}{ Visit no. } & \multicolumn{3}{|c|}{ No. of patients } \\
\hline & \multirow[t]{2}{*}{ Total } & \multicolumn{2}{|c|}{ Result of examination } \\
\hline & & Positive & Negative \\
\hline $\begin{array}{l}1 \\
2\end{array}$ & $\begin{array}{l}167 \\
107\end{array}$ & $\begin{array}{r}60(35.9 \text { per cent } \\
1(0.9 \text { per cent. })\end{array}$ & $\begin{array}{l}107 \\
106\end{array}$ \\
\hline
\end{tabular}

form of dysuria and/or urethral discharge. Only one of the 107 patients who were negative at the first visit was positive at the second examination. This patient was free from symptoms. Of the 106 remaining patients who were negative by conventional methods after two consecutive visits, 94 were investigated by the FA technique after prostatic massage (Table II). Specimens from ten patients fulfilled the criteria of intact coccal morphology, correct size, and intense fluorescence. In five of these ten patients the urethral secretion collected immediately before prostatic massage was also FA-positive. One of the ten FA-positive patients complained of urethral discharge, whilst nine were completely free from symptoms. Of the 84 FA-negative patients, eleven had symptoms of urethritis, whilst 73 were symptomfree. Conventional direct microscopy and cultures of specimens taken from the urethra both immediately before and after prostatic massage were negative in all 94 cases investigated by the FA method.

TABLE II Results of direct FA test on urethral material after prostatic massage related to symptoms of urethritis in 94 males reported as gonorrhoea contacts in whom two consecutive urethral cultures had been negative

\begin{tabular}{|c|c|c|c|}
\hline \multirow[t]{2}{*}{$F A$ test } & \multicolumn{3}{|l|}{ No. of patients } \\
\hline & Total & Symptoms & No symptoms \\
\hline $\begin{array}{l}\text { Positive } \\
\text { Negative }\end{array}$ & $\begin{array}{l}10^{\mathrm{a}} \text { (10.6 per cent.) } \\
84\end{array}$ & $\begin{array}{r}1 \\
11\end{array}$ & $\begin{array}{r}9 \\
73\end{array}$ \\
\hline Total & 94 & 12 & 82 \\
\hline
\end{tabular}

${ }^{\mathrm{a}}$ Five of these were also positive in urethral secretions collected before prostatic massage.

Eight of the ten FA-positive patients stated that they had not been treated with antibiotics during the 6 months immediately preceding the investigation. One patient had taken three to four penicillin tablets (Calciopen- ${ }^{\circledR}$ ) each of 600,000 i.u. for a throat ailment more than 3 weeks before the FA investigation. Another patient had been treated with an antibiotic 1 month before a positive FA test (see Case report). 


\section{Case report}

A 45-year-old married man had been treated for prostatitis in 1969. After coitus with a casual partner in the autumn of 1971 he contracted gonorrhoea, which was treated with oral tetracycline for 10 days. His wife was treated at the same time for uncomplicated gonorrhoea with $300 \mathrm{mg}$. doxycycline in a single oral dose. Two follow-up examinations were negative in both these patients.

The husband had sexual intercourse with a casual partner in December, 1971, and with his wife on January 1, 1972. He was examined five times between Jan. 7 and Feb. 3 because of a urethral discharge and dysuria. The findings on palpation of the prostate gland were normal. Treatment was started on Feb. 3 with oxytetracycline $0.5 \mathrm{~g}$. twice daily for 10 days despite negative bacterial tests and he subsequently became symptom-free.

During the same time the wife was treated twice for gonorrhoea with oral ampicillin, 2 doses of $1 \mathrm{~g}$. with a 5-hr interval. Two follow-up examinations were negative. She stated that she had had sexual intercourse, but only with her husband 3 to 4 days before the diagnostic examinations. On Feb. 21 uncomplicated gonorrhoea was again confirmed in the wife, who was treated with ampicillin as before. Two consecutive follow-up examinations with direct microscopy and cultures were again negative. She stated that the only possible occasion for re-infection was coitus with her husband on Feb. 14. In all her four infections the organism showed full sensitivity to all the antibiotics tested, including ampicillin.

The husband was examined on Feb. 25, after having had a discharge for about 1 day. He stated that his wife had been his only sexual partner during the preceding 2 months. Direct microscopy and culture of urethral specimens gave negative results, and these specimens were also negative on March 3, when the FA test was done and was found to be positive in the specimen taken after prostatic massage although it was negative in a specimen taken before. The findings on prostatic palpation were normal as before. Oral treatment with ampicillin $1 \mathrm{~g}$. three times daily for 7 days was started. At follow-up examinations 5 and 9 weeks after treatment the FA test was positive both before and after prostatic massage. Since the FA test after prostatic massage was still positive after 10 weeks (June 15), oral doxycycline 100 mg. was given twice daily for 7 days; the FA test after prostatic massage then became negative.

\section{Discussion}

Investigations by Juhlin (1968) and Wallin (1971) have shown that the epidemiological significance of a small group of undetected infected individuals may be far-reaching. Patients who attend because they have been reported under the Swedish Law against Infectious Diseases as contacts of patients with gonorrhoea constitute between 7 and 27 per cent. of the total (Lidén, 1969; Hansson, 1971), and therefore account for a considerable number of the patients in this category. One of the reasons why the source of infection is not detected in more than roughly 60 per cent. of cases (Hammar and Ljungberg, 1972), may be that, although patients actually constituting sources of infection are examined, the methods of detection are not sufficiently sensitive.

In this study gonorrhoea was diagnosed at the first visit in sixty of the 167 cases ( 35.9 per cent.). Only one additional case ( 0.9 per cent.) was diagnosed in the remaining 107 patients at the second visit by routine methods, whereas the FA test was positive at this time in ten more (10.6 per cent.) of the 94 males in whom this test was performed.

Since the fluorescent antibody technique for gonococci was first described (Deacon, Peacock, Freeman, and Harris, 1959), several investigations have been published, and the method is considered to be specific and sensitive (Danielsson, 1965; Mouton, 1966). Lind (1967), however, reported negative findings which were due to the masking effect of non-specific background staining. But when RB-200-labelled antistaphylococcal globulin is added, the result is not only the inhibition of cross-reactions but also a counterstain effect, which reduces the disturbing effect of the background staining (Danielsson, 1965). Thus, with strict criteria for reading and the use of counterstaining, false positive results due to non-specific staining and cross-reactions with other bacteria, with the exception of meningococci, are avoided. The conventional bacteriological methods used exclude $N$. meningitidis as a source of error, but not the possibility of the presence of L-phase organisms. Meningococci rarely occur in specimens of urogenital material and they give in general a much weaker fluorescence with the FA method that we used (Danielsson, 1963, 1965; Lind, 1967). The bacteria detected by the FA test in this study may therefore be considered to be $N$. gonorrhoeae.

Pariser and others (1964) and Danielsson and Molin (1971) demonstrated gonococci by the FA technique in the prostatic secretion in solitary cases of asymptomatic males exposed to gonorrhoea. In the present investigation, the direct FA test was positive after prostatic massage in ten of the 94 contacts who had twice given negative results by direct microscopy and routine cultures with an interval of at least 1 week. In five of these ten patients the FA test was also positive in urethral specimens taken before prostatic massage. Although the prostatic massage was performed after micturition, contamination of the expressed prostatic secretion by urethral material cannot be entirely avoided (Stamey and others, 1965). A positive test after prostatic 
massage does not, therefore, exclude the possibility that the gonococci originated in the urethra. On the other hand, gonococci detected in the urethra may originate from the prostate gland. The possibility of the prostate acting as a reservoir for gonococci must therefore be taken into consideration.

The FA method gives no indication of the viability of the detected gonococci. Lucas, Price, Thayer, and Schroeter (1967) have shown in a study in vitro that killed $N$. gonorrhoeae are not all lysed and that strong fluorescent antibody staining may be observed up to 24 days after exposure to bactericidal concentrations of penicillin. In this study only two of the ten FA-positive patients had been treated with antibiotics during the preceding 6 months. Moreover, the antibiotics were given about 1 month before the FA tests were found to be positive, so that it is unlikely that the findings in these two cases were due to the presence of non-viable gonococci.

On the other hand, there are strong indications that the patient described above in the case report had been a carrier of viable gonococci that had not been detected by direct microscopy or routine cultures of the urethral or prostatic secretions. It is conceivable that the prostate gland had acted as a reservoir for gonococci. The poor accessibility of most antibiotics to the prostatic secretion has been described by Winningham, Nemoy and Stamey (1968) and Stamey, Meares, and Winningham (1970). Of the antibiotics with which this patient had been treated since being infected by a casual contact in December, 1971, only doxycycline seems to penetrate the prostatic epithelium (Hessl and Stamey, 1971). It was, in fact, only after treatment of the patient with doxycycline for one week that the FA test after prostatic massage became negative.

Cultures taken simultaneously with specimens for the FA test were negative in the ten FA-positive patients. But a negative culture does not exclude the possibility of a positive FA finding representing viable gonococci. Stamey, Fair, Timothy, and Chung (1968) detected antimicrobial activity in human prostatic secretion. Thus, the $N$. gonorrhoeae detected by the FA test in this investigation could be residual gonococci in cases in which healing had not yet been complete.

L-phase organisms may have a partially defective cell wall (Hijmans, van Boven, and Clasener, 1969) without losing their antigenicity. Consequently, it should also be possible to detect them by FA testing (Danielsson, 1972) in cases in which cultures on hypotonic media are negative. Gnarpe, Wallin, and Forsgren (i972) were able to detect $N$. gonorrhoeae as well as L-phase organisms in cultures made on osmotically stabilized media.
In the present study $N$. gonorrhoeae was detected in 10.9 per cent. of the male contacts investigated by the direct FA test when the routine tests had been negative. These FA-positive cases constitute an epidemiologically significant pool of infected males who are usually asymptomatic. Furthermore, there is always the risk that complications may develop. The direct FA test, although time-consuming, must therefore be regarded as a valuable supplementary method in the diagnosis of gonorrhoea.

\section{Summary}

In a study of 167 males named as contacts of patients with gonorrhoea and who were referred under the Swedish Law against Infectious Diseases, gonorrhoea was diagnosed at the first examination by direct microscopy and/or conventional bacteriological cultures in sixty cases ( 35.9 per cent.), but only in one additional case out of $107(0.9$ per cent.) at the second visit. Examination by the direct fluorescent antibody technique of urethral material obtained after prostatic massage in 94 patients with two consecutive negative cultures revealed a further ten cases of gonorrhoea. Five of these were also FApositive before prostatic massage. Only one of the ten FA-positive patients had symptoms of urethritis. Bacteriological cultures of urethral secretions in all? cases investigated by the FA test were negative both before and after prostatic massage. This study demonstrates that, when there is a suspicion of a gonorrhoeal infection and the conventional culture is negative, further cases of gonorrhoea can be diagnosed by the direct FA test. Such FA-positive patients probably play an epidemiological role as sources of infection.

\section{References}

Danielsson, D. (1963) Acta derm.-venereol. (Stockh.), 43, 451

(1965) Acta path. microbiol. scand., 64, 267

(1972) Personal communication

and Molin, L. (1971) Acta derm.-venereol. (Stockh.), 51, 73

Deacon, W. E., Peacock, W. L., Jr., Freeman, E. M., and Harris, A. (1959) Proc. Soc. exp. Biol. (N.Y.), 101,322

ErIcsson, H. M., and Sherris, J. C. (1971) Acta path. microbiol. scand., Sect. B., Suppl. 217 ('Antibiotic sensitivity testing')

GNarPe, H., WalliN, J., and Forsgren, A. (1972) Brit. F. vener. Dis., 48, 496

Hammar, H., and Ljungberg, L. (1972) Acta derm.venereol. (Stockh.), 52, 233

Hansson, H. (1971) Lakartidningen, 68, 4239

Heijer, A. (1967) Acta derm.-venereol. (Stockh.), 47, 198

Hessl, J. M., and Stamey, T. A. (1971) f. Urol. (Baltimore), 106, 253 
Hijmans, W., van Boven, C. P. A., and Clasener, H. A. L. (1969) 'Fundamental biology of the L-phase of bacteria' in 'The Mycoplasmatales and the L-phase of Bacteria', ed. L. Hayflick, p. 67. Appleton-CenturyCrofts, New York.

HöFER, W. (1954) Derm. Wschr., 129, 297

JuHlin, L. (1968) Acta derm.-venereol. (Stockh.), 48, 82

LANDGReN, B-M., Molin, L., and NyströM, B. (1971) Lakartidningen, 68, 4897

LIDÉN, S. (1969) Ibid., 66, 907

LIND, I. (1967) Acta path. microbiol. scand., 70, 613

LuCAS, J. B., Price, E. V., Thayer, J. D., and Schroeter, A. (1967) New Engl. f. Med., 276, 1454

Molin, L. (1970) Social med. T., 47, 87

Mouton, R. P. (1966) Dermatologica (Basel), 132, 343

PARISER, H., FARMER, A. D., and MARINo, A. F. (1964) Sth. med. F., 57, 688

RINGERTZ, O. (1960) Acta path. microbiol. scand., 48, 105

Romanus, R. (1952) Nord. Med., 47, 343

Stamey, T. A., Fair, W. R., Timothy, M. M., and Chung, H. K. (1968) Nature (Lond.), 218, 444

- Govan, D. E., and Palmer, J. M. (1965) Medicine (Baltimore), 44, 1

, MEARES, E. M. Jr., and WinNingham, D. G. (1970) f. Urol. (Baltimore), 103, 187

StARCK, V. (1966) Nord. Med., 76, 811

WALLIN, J. (1971) Lakartidningen, 68, 199

WILlcox, R. R. (1970) Brit. F. vener. Dis., 46, 217

Winningham, D. G., Nemoy, N. J., and Stamey, T. A. (1968) Nature (Lond.), 219, 139
Identification de Neisseria gonorrhoeae par la technique de la fluorescence directe chez les contacts masculins

\section{SOMMAIRE}

Dans une étude de 167 hommes désignés comme contacts de malades atteints de gonorrhée, en application de la loi suédoise contre les maladies infectieuses, la gonococcie fut reconnue au premier examen par microscopie directe et/ou par culture bactériologique dans 60 cas $(35,9$ pour cent), mais seulement dans un cas supplémentaire $(0,9$ pour cent) lors de la seconde visite. L'examen par la technique de mise en évidence de l'anticorps par l'immuno fluorescence directe du matériel urétral obtenu après massage prostatique chez 94 sujets ayant eu deux cultures consécutives négatives, permit de retrouver 10 autres cas de gonococcie. Cinq de ces cas étaient aussi positifs en immuno-fluorescence avant le massage prostatique. Un seul de 10 malades positifs en immuno-fluorescence avait des symptômes francs d'urétrite. Les cultures bactériologiques des sécrétions urétrales dans tous les cas examinés furent négatives à la fois avant et après le massage prostatique. Cette étude montre que, lorsqu'il y a suspicion de gonococcie et que la culture conventionnelle est négative, des cas supplémentaires de gonococcie peuvent être diagnostiqués par le test d'immunofluorescence direct. De tels malades, positifs avec cette technique, jouent probablement un rôle épidémiologique en tant que source d'infection. 